\title{
On Fostering Students' Cultural Awareness in Teaching English
}

\author{
Zhang Li \\ School of Foreign Languages \\ Yanan University(YAU) \\ Yanan, China
}

\author{
Wang Tiantian \\ School of Foreign Languages \\ Yanan University(YAU) \\ Yanan, China
}

\begin{abstract}
This paper aims to develop students' cultural awareness and improve their performance of cross-cultural communication. The author thinks there are four levels of cultural awareness, "Four No's" - No Sense, No Reservation, No Passion and No Culture. If one has experienced "from No to No" pattern, he becomes "an old X-language hand". As an English teacher, one will obtain the goal by leading much English culture in the course of the four-basic-skill teaching. This paper will mainly discuss three of the four basic skills - listening, speaking and reading to foster students' cultural awareness in English learning. Hopefully, after several years of English learning, students can adapt to English culture and communicate with native English speakers appropriately without cultural troubles.
\end{abstract}

Keywords-cultural awareness; culture; cross-cultural communication; English teaching

\section{INTRODUCTION}

The $21^{\text {st }}$ century is an information age. Information is everything, and it is everywhere nowadays. Therefore, in this new era, to learn a second language, especially English, is more essential than that ever before. Learning a second language is not only a simple process of learning the language itself but also culture of its country. Therefore, it is important for students to develop cultural awareness in second language learning.

Professor DENG Yanchang once said, "Learning a foreign language well does not simply mean mastering its pronunciation, grammar and vocabulary. In fact, the learning of a language is inseparable from the learning of its culture". ${ }^{11]}$ Culture is the collection of all the beliefs, customs, traditions and thinking patterns in a nation or a group of people live together. That is, the total accumulation of all the material and spirit shared and passed down through generations in a particular, relatively steady group. In this information age, most countries encourage students to learn a second language as an educational policy. When a language is taught and meanwhile learned, some kind of related culture must be instilled. That is the only way to learn a language well. As a student, it is not enough to grasp only vocabulary, grammar and pronunciation, or language itself, but also to sense the importance of the relationship between culture and language and to understand that learning a language well knows its culture well. Then, he can speak and behavior properly at the proper time and on the proper occasions. As a teacher, the goal to teach a second language must be clear and definite. Chinese scholar Chen Shen mentions that our goal is to train our students to be skilled in listening, speaking, reading, and writing and at the same time be familiar with the foreign culture and can use English appropriately according to specific cultural situations. The fundamental function of language is to communicate. A successful English teaching is to help language learners develop a good communicative ability. But after many years of English learning, most students still find it difficult to communicate with native English speakers. It is because Chinese culture is different from that of Englishspeaking countries and Chinese students may transfer their mother tongue references of language to English performance and fail to communicate effectively just for the lack of the comprehension of western culture. Therefore, it is greatly important and necessary to cultivate and increase students' cultural awareness. English teachers are faced with one problem - equipping students with the knowledge of cultural background and improving their cross-cultural communicative competence in English teaching. In other words, teachers must not only help improve students' linguistic ability, but also focus on developing students' cultural awareness. It is difficult to cultivate and enhance learners' cultural awareness although they have realized the differences because they unconsciously impose their native culture onto the foreign language, which greatly hinders an effective intercultural communications.

\section{Cultural AWAREness}

\section{A. Definition of cultural awareness}

With the increasing exchange and communication between eastern and western countries, cultural conflicts have become obviously acute. That does not correlate with language itself, but with the beliefs, customs and thinking patterns, etc. If one does not know about these of another country, he cannot get along well with the people there, just because he lacks the cultural awareness. Cultural awareness is the foundation of communication. The success of interaction or communication depends a lot on one's possession of cultural awareness or not.

Then, what is cultural awareness? According to Dr. Brian Tomlinson of Leeds Metropolitan University, "Cultural awareness is a gradually developing inner sense of the equality of cultures, an increased understanding of your own and other people's cultures, and a positive interest in how cultures both connect and differ. Such awareness can broaden the mind, increase tolerance and facilitate international communication." [2] 
Cultural awareness matters when one communicates with a foreigner or even a native not in a same cultural circle. Whether one can live overseas happily or negotiate in crossnational trades successfully or not, it depends on one's cultural awareness to a great degree rather than the proficiency of the language they speak.

\section{B. The levels of cultural awareness}

Cultural awareness is to know and understand the social regulation, the outlook of values and beliefs of the target culture. According to the degree people know about the target culture, the author of this paper thinks there are four levels of cultural awareness.

The first level is No Sense, which means one is not aware of the target culture. He may think the culture of some country is the same as that of his own. He does not think the culture matters but only language does.

The second level is No Reservation. At this stage, one may put the wholehearted love to the new culture. He is greatly interested in the brand-new culture. He thinks this is the perfect cultural pattern, which is modern and humanized under the interpretation of the native speakers. This is also called the stage of honeymoon, which is to love the other partner without reservation.

The third level is No Passion. After a short while staying overseas, one may homesick and he finds the new culture is boring, beyond logic and comprehension. $\mathrm{He}$ is missing his homeland and he has no passion for the place and the culture he was totally interested in.

The fourth level is No Culture, which means one thinks everything is what it is. It should be like that. Now, he has been accustomed to the culture in which he is. He does not sense he is in a different culture. For example, if you ask a Chinese person, "What is the Chinese culture", he may have no answer. But if you ask a foreigner the same question who lives in China for not a long period, he may say, "Chinese culture is that no one will excuse when he sneezes in public". After many years in China, the foreigner has been "an old Chinese hand". And you ask him, "What is the Chinese culture?" He may be lost in thought, and then he will say, "Chinese culture is everywhere and it is nowhere in China, because I'm a Chinese now. I do not think something is too odd to me to be called Chinese culture."

Hence, the "Four No's" is the four levels for a person to experience and eventually grasp the target culture, which is "from No to No". The whole process can interpret the course one goes through the path of cultural awareness. Anyhow, cultural awareness is of great importance for a second language learner and teacher to adopt it and to practice it. When you have passed the four levels of the cultural awareness, it proves that you have been skilled in a second language and the second culture.

\section{DeVeloping STUdents' CULTURAL AWARENESS IN ENGLISH TEACHING}

Learning to communicate across culture is to consider what people mean when they talk about culture. The problem for cross-cultural communication is that speakers of different languages, members of different cultures and people in various situations use language and non-language codes differently when they communicate.

\section{A. English listening teaching in middle school}

English listening is probably the most difficult task for most students of English as a second language. Listening is the ability to identify and understand what others are saying. This involves understanding a speaker's accent or pronunciation, his grammar and vocabulary, and grasping his meaning.

As for the four basic skills (listening, speaking, reading and writing) to learn English, listening is one of the fundamental language skills. Some students think that the biggest difficulty is listening comprehension, and even they have difficulty in understanding their teachers' lessons. It's difficult for a middle school student to understand the listening material, if he has not had enough vocabulary and the ability of grasping the meaning. They have their own listening habits. Some students try to understand each word or each sentence, but not to grasp the meaning or to understand the context or cultural background knowledge.

We know the difference between mother language and foreign language is the environment. Students can soon master their mother language well, they can hear a lot before they can say something. As for a foreign language, students can only meet it in classes or some activities. So teachers should let students be familiar with the western culture. Lack of cultural background, the contextual knowledge of the foreign language can present an obstacle to listening comprehension. Therefore, when listening, students may make some simple notes, for example, the names of people and places, time, age, distance, occupation, figures and so on to get a better understanding of the context. But sometimes, it's still difficult for them to grasp the meaning. If students familiar with the cultural background, they can make it clear directly. For example, there is one sentence, which is "Jane is not a 'people person'. Luckily, her job does not require her to spend a lot of time with clients" "[3]. When listening to this sentence, students may be puzzled about "people person". The teacher should tell students the meaning of the "people person". "People person" means someone who likes being with other people and who is good at working with people. What's more, it's better for the teacher to tell them the cultural background knowledge. This term became popular in the 1990s. It was first used in corporation as a way to describe friendly people who are good at sales and customer service. Then students can get a better understanding about this phrase.

Another example, "The editor thought the story about the president's girlfriend was too hot to handle, so he refused to print it." Students may puzzle about the meaning about "too hot to handle". "Too hot to handle" means "difficult; hard to deal with", which comes from baseball, referring to a ball hit so hard that it can't be caught. In this phrase, "hot" means "lively" 
or "powerful", and "handle" means "take care of" or "pick up". The phrase is now used to describe any situations that it's hard to deal with or problematic. When listening, students should be active listeners and they are also interested in understanding what the other person is thinking, feeling or what the message means and they are active in checking out their understanding before they respond with their own new message.

While listening, the student is likely to decide that he or she doesn't understand what is being said. At the point, many students just turn out or get caught in an internal dialogue trying translating a specific word. Some students convince themselves that they are not able to understand spoken English well and create problems for themselves. The reason for this is the cultural background knowledge. We can see that in English listening teaching, there are some difficulties aroused by the lack of cultural awareness. So, if students know the cultural background knowledge and they are familiar with the context, they can easily grasp the meaning.

\section{B. Oral English teaching in middle school}

The aim of oral English is communication. Communication means that people speaking to one another can understand each other. Many students have studied English for years, but they still have some difficulty in communicating with native speakers. Some know a lot of words and expressions, but they are unable to discern them when native speakers use them. One of the most important reasons is the cultural awareness.

Oral English includes pronunciation, vocabulary, grammar and sentence patterns. If students develop an ability to put these all together in a right way, they have mastered the linguistic competence. But this is not enough. Speaking is the most obvious form of communication between people. The student should have the ability to grasp language's communication function and thinking ability on cultural background knowledge.

Oral English learning is a matter of practice but not a matter of learning the theory. That is to say, the use of language is more important than knowing about the usage of language. For example, an important question about eating out, at the beginning, is who pays for the meal. If a friend of yours suggests you have lunch with him, you might simply say something like this, "I am afraid it'll have to be some place inexpensive, as I don't have enough money." The other person may say, "OK, I'll meet you at McDonald's." This means it is agreed that the two will go Dutch, that is, each person pays for himself. He may also say, "Oh, no, I want to take you to lunch at Italian restaurant's," or "I want you to try the steak there, it's great." This means the person intends to pay the bill for both of you, if you feel friendly towards this invitation, you may simply say, "Thank you, that would be nice." Therefore, students may be confused about this part, teachers should tell students about the American customs, and teachers should teach them in advance. We know that American customs about who pays for dates are much the same as those in other parts of the world. American women used to expect men to pay for all the meals. But, today, a woman who is working in the business world will usually pay her way during the day. However, if a man asks her to attend something special outside the normal working hour, cocktails or dinner or a dance or movie - the invitation itself means "come as my guest". So, as you can see, it's a polite thing to make the situation clear at the very beginning.

Lack of clarity will often cause some difficulties. In oral English, "Thank you" is frequently used in English-speaking countries between family members, even for the minor favor. Take the simple dialogue as an example.

A: Would you like a piece of cake?

B: Yes, thank you.

A: Would you like another one?

B: May I? Yes, thanks.

A: How about another one?

B: Oh, no, thank you. ${ }^{[4]}$

So we can see that how often English-speaking people say "thanks". However, in China, such polite expressions are often omitted, especially among close friends and family members. So teachers should tell such kind of cultural difference to students. It's clearly stated that the difference between English and Chinese in English speaking.

In an English class, students can't understand the materials sometimes, because they lack knowledge of cultural background. So when they are speaking to foreigners, it's important to follow the customs of the foreign country. If they are invited to a home in Britain, it's good manners to refuse or accept the invitation, either by writing or by telephoning. When they go to the party, it's polite to arrive on time. They should shake hands with their host and any other guests. Then they can start their conversation. It's impolite for someone to ask a series of questions like, "Where are you from?" "What is your job?" "What are you doing?" The Englishmen may think "It's none of your business." So such kind of opening-up questions destroys the whole conversation, because they are not appropriate. That is the cultural differences. As we all know, the traditional Chinese philosophy of man's unity with heaven, the Chinese believe in a harmonious relationship between man and nature. However, English-speaking people, like other westerners, worship individuality. They believe that man is independent of nature and must struggle with nature to meet his needs. So, Englishmen place a high value on privacy, such as age, salary, marriage or family background. While in China, they do not consider age or salary as privacy. However, if they do not follow the culture taboos and ask others' age, they may invade others' privacy. Although students learn these conversations in their English classes, they are still not appropriate expressions in the English-speaking countries. Therefore, students should know that and they should avoid asking such questions unless foreigners indicate clearly that they do not mind. So, in class, teachers should teach some cultural background knowledge to students.

Sometimes students are completely confused how to greet each other. The teacher has taught them usual sentences people use in greetings, but he has never mentioned the cultural differences. Meanwhile, students will also need to master some skills in culturally appropriate communication and behavior for the western culture. Consequently, cultural awareness is necessary if students are to develop an understanding of the western culture and their own culture. 


\section{English reading teaching in middle school}

Reading is a complex process of the interaction between the writer's language and the reader's prior background knowledge. Indeed, in the reading process, readers' capacities of reading are very important, but sometimes they can't read between the lines except by the help of background knowledge of culture, because the meaning of words are acquired in a certain circumstance of culture. Chinese people read Chinese articles without the difficulties aroused by cultural background. For example, Chinese proverbs like, "Chengmen shihuo, yangji chiyu(城门失火,殊及池鱼)”, “Yongren zirao(庸人自扰)”, “Zhanggong chijiu Ligong zui(张公吃酒李公醉)” will not influence Chinese people to understand the article. However, when Chinese students read English articles, differences between Chinese and western cultures will be aroused. Meantime, if a Chinese student does not know about western culture, such as histories, customs, life style and so on. He or she may fail to understand the exact meaning of the texts.

Sometimes, English teaching has just focused on the language form and ignored the effect of background knowledge of culture. However, the cultural background knowledge is rather extensive. Lacking of it may keep students from comprehending language. For example, there is a sentence "Peter has a very heavy beard - even though he shaves every morning, he gets a five o'clock shadow by lunchtime." The syntax of the sentence is very simple. However, students did not understand the sentence at that time until their teacher explains to them. The typical American workday ends at "five o'clock" in the afternoon. A "shadow" is a patch of darkness, or a hint of the presence of something. After spending a full day at work for 8 or more hours, many men have a noticeable growth of facial hair, which is a dark like a "shadow" and hints at the beard that would grow if left unshaven. Then students realize the real meaning of this sentence. From this case, we can see that to comprehend the language not only depends on the comprehension of vocabulary and grammatical structures, but also depends on the comprehension of relevant background knowledge of culture.

In English reading, culture and language can't be separated. Every kind of language is created and developed in a certain period of society. When considering how to teach reading to students, the most important point is to teach them to get the general idea. Have students read through the text once; their main purpose during the first reading is to achieve a general understanding of the text. Another example: "Many of the city's fat cats at that steak restaurant on First Avenue." It may puzzle students. "Fat cats" refers to a person who has great wealth and power. This term comes from 1920s, when it was used to describe wealthy contributors to American political parties, then after teachers explain these, students would understand it.
As we all know, foreigners like to use slang in their speeches or articles, but it's difficult for Chinese students to understand the slang in the textbook sometimes. Students do not get the real meaning of most slang unless teachers teach them why foreigners say so. For example, "July 4th is Independence Day in the United States. Happy birthday, Uncle Sam". ${ }^{[5]}$ Maybe students can guess the meaning of "Uncle Sam" according to the context. However, if teachers tell the definition and cultural background of this phrase in advance, it will be more helpful for students to understand. Thus, during the war of 1812 between the United States and England, a man named Samuel Wilson provided supplies to the American troops. Wilson was known as "Uncle Sam", and he stamped his supplies with "US", which stood for both "United States" and "Uncle Sam". Since then, "Uncle Sam" has been a symbol for the country, especially in times of war. So "Uncle Sam" is a patriotic figure who symbolizes the United States. After explaining those, students can make themselves clear.

\section{CONCLUSION}

With the development of anthropology, cross-cultural communication has become a fashion. ${ }^{[6]}$ It demands students in 21 st master cross-culture communicative ability. A lot of practice has proved that the obstacles which affect the student's communicated skills are the aspect of culture. And teachers should pay more attention to the culture instruction in the foreign language teaching and foster the students' culture consciousness at the same time. As language teachers, they should not only introduce the cultural background concerned the context, but also ask students to read more books combined cultural knowledge with the communication rules. By doing so, students can get a strong consciousness of culture acquisition little by little. Hence students will be improved efficiently in cross-cultural communication.

\section{REFERENCES}

[1] Fan Hu-ping and Jiang Hong-xia,"Culture and English language teaching”, Journal of Gansu Education College Social Science, 1977, pp. 79-82.(In Chinese)

[2] B. Tomlinson, "Seeing more between the lines", The Guardian Weekly, Learning English, 2001, pp21-27.

[3] J. Richards and P. John, Longman Dictionary of Language Teaching and Applied Linguistics. Essex: Longman, p985, 1992.

[4] Liu Xi-juan and Cheng Fu-lin, "How to develop Middle School Students' English Speaking Competence", Journal of Binzhou Educational Institute, 2003, pp.64-66.(In Chinese)

[5] M. Montgomery, Language and Social life. Georgia: University of Georgia Press, p189, 1994.

[6] Hu Wen-zhong, Culture and Communication, Beijing: Foreign Language Teaching and Research Press, p79, 2000.(In Chinese) 